\title{
ANALYSES OF TOTAL ELECTRON CONTENT VARIATIONS OVER NORTHERN AND SOUTHERN NIGERIA
}

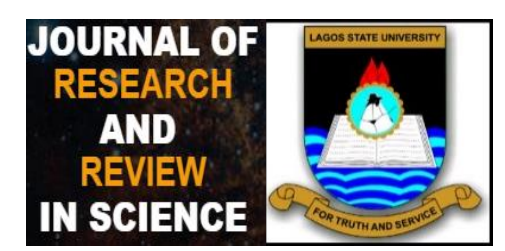

Aghogho Ogwala ${ }^{1}$, Emmanuel Olufemi Somoye ${ }^{1}$, Oluwole Oyedokun ${ }^{2}$, Rasaq Adeniji-Adele ${ }^{1}$, Eugene Onori ${ }^{1}$, Oluwafunmilayo Ometan ${ }^{1}$, Abiola Ogungbe ${ }^{1}$, Cornelius Ogabi ${ }^{1}$, Olujimi Adejo ${ }^{1}$, Kayode Oluyo ${ }^{1}$, Adesina Sode ${ }^{1}$

${ }^{1}$ Department of Physics, Faculty of Science, Lagos State University, Nigeria

${ }^{2}$ Department of Physics, Faculty of Science, University of Lagos, Nigeria

\section{Correspondence}

Aghogho Ogwala, Department of Physics, Faculty of Science, Lagos State University, Nigeria.

Email:ogwala02@gmail.com

\begin{abstract}
:
Introduction: Total Electron Content (TEC) is a parameter of the ionosphere that produces great effect on radio signals. We present the diurnal and seasonal variations of vertical Total Electron Content (vTEC) during the ascending phase of solar cycle 24 . A moderate solar activity year (2011) with sunspot number, $R z=55.7$ is used in this study.

Aims: To compare the diurnal and seasonal variations of TEC at Southern and Northern Nigeria.

Materials and Methods: TEC deduced from the dual frequency GPS measurements obtained at two ground stations namely: Ahmadu Bello University Zaria $(A B U Z)$ with longitude $7.39^{\circ} \mathrm{E}$ in the north and University of Nigeria Enugu (UNEC) with longitude $7.30^{\circ} \mathrm{E}$ in the south are considered. Both stations are located within the same longitude and has a latitudinal difference of $4.74^{\circ}$ in the Nigerian equatorial ionosphere (NEI). Results: The diurnal variation of TEC shows a steep increase starting from sunrise, reaching daytime maximum between $13-15$ LT at UNEC and 14 - 16 LT at ABUZ, then falls to a minimum at sunset. Dawn depression occurred at the same local time of $04 \mathrm{LT}$ at both stations. On a seasonal scale, Pre- and post-midnight values were highest during the Equinoxes, followed by December solstice and least in June Solstice season at ABUZ. Pre- and post-midnight values were also higher during the Equinoxes than the Solstice season at UNEC, although they are about the same range. Also, TEC values are observed to be slightly higher for all hours and seasons at Enugu in the south than Zaria in the north except during March equinox at Zaria where TEC values were higher during the daytime. Conclusion: This implies that there could be little variations in TEC even within the same latitudinal zone.
\end{abstract}

To Keywords: TEC; Diurnal; Seasonal; variability.

This is an open access article under the terms of the Creative Commons Attribution License, which permits use, distribution and reproduction in any medium, provided the original work is properly cited.

(C) 2018 The Authors. Journal of Research and Reviews in Science - JRRS, A Publication of Lagos State University 


\section{INTRODUCTION}

The ionosphere is a very important part of the earth's atmosphere (above $60 \mathrm{~km}$ altitude) most of which lies in space. Some spacecraft in low earth orbit such as space shuttle and the international space station orbit through the ionosphere. This region affects radio waves as it makes long distance High Frequency radio communication possible, and also affects satellite communications. The ionosphere causes a variation in the intensity of radio signals i.e. fading as a result of irregularities (inhomogeneity in electron density) [20]. The variable nature of the ionosphere, especially over the equatorial/ low latitudes poses serious threats to High frequency (HF) communications [2]. This region exhibits unique features, for example, noon bite-out, spread-F, Equatorial Electrojet (EEJ), Equatorial Plasma Bubbles (EPB), etc.

Recently, rockets and satellites measurements have been used to deduce electron density profiles known as total electron content (TEC), by taking into consideration the differential absorption between the ordinary and extraordinary waves [12]. TEC is a parameter of the ionosphere that produces most of the effects on radio signals. The TEC measurements obtained from dual frequency GPS receivers is one of the most important methods of investigating the earth's ionosphere. TEC is significant in determining scintillation, group and phase delays of radio waves through a medium.

TEC is the total number of electrons integrated between two points, along a tube of one meter square cross section i.e. electron columnar number density. It is measured in multiples of TEC units defined as 1 TECU $=10^{16} \mathrm{el} / \mathrm{m}^{2}[8]$.

$T E C=\int n_{e}(s) d s$

TEC obtained from Global Navigation satellite systems (GNSS) are of two types (i) slant TEC (sTEC) and (ii) vertical TEC (vTEC).

The VTEC is determined by integrating electron density on a perpendicular to the ground standing route while STEC is obtained by integrating electron density over any straight path from satellite to the receiver. Since slant TEC is dependent on the ray path geometry through the ionosphere, it is desirable to calculate an equivalent vertical value of TEC which is independent of the elevation of the ray path. Hence, VTEC is obtained from the sTEC by using the Modified SingleLayer Model Mapping Function (MSLM) given in equation (2).

$F(z)=\frac{1}{\cos z^{\prime}} \quad$ with $\sin z^{\prime}=\frac{R}{R+H} \sin \alpha z$
Where $\mathrm{H}=506.7 \mathrm{~km}$ and $\alpha=0.9782$ (when using $\mathrm{R}=$ $6371 \mathrm{~km}$ and assuming a maximum zenith distance of $\left.80^{\circ}\right)$.

There is a phase advance and group delay when a wave propagates through the ionosphere. Thus, a GNSS can measure both the phase and pseudorange of a signal passing through the ionosphere by using the linear combination of the two frequencies, L1 (1575 $\mathrm{MHz})$ and L2 (1228 MHz) as illustrated in Figures 1 for TEC estimation.

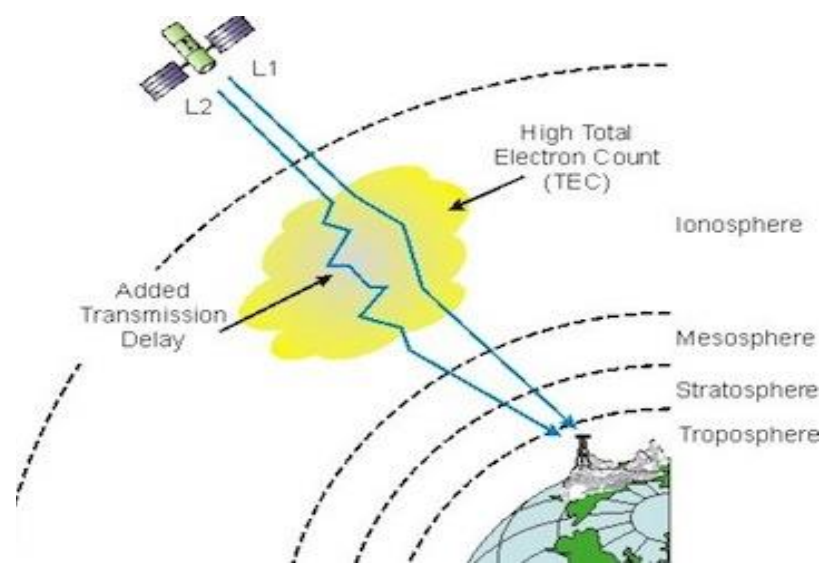

Figure 1: Signal affected at ionospheric region [1].

This compensate for the ionospheric delay to first approximation. Since the refractive index of the dispersive ionosphere is a function of frequency, the ionospheric time delay at the L1 carrier frequency of $f_{1}$ is given in [16] as

$t_{1}=40.3 \times\left(\frac{T E C}{c . f_{1}^{2}}\right)$

where $C$ is speed of light in free space. Take the time delay between the two frequencies as $\Delta t=t_{2}-t_{1}$. Thus,

$\Delta t=\left(\frac{40.3}{C}\right) \times \frac{T E C}{\left[\left(1 / f_{2}^{2}\right)-\left(1 / f_{1}^{2}\right)\right]}$

Thus, $\Delta t$ measured between the $L 1$ and $L 2$ frequencies is used to evaluate TEC along the ray path. Using equation (4) to evaluate TEC with only the pseudorange data produces a noisy results [17]. The pseudorange TEC estimate is so noisy and thus results in a poor measurement, while using the phase to calculate the TEC gives ambiguous results. The best approach is to use the noisy pseudorange measurement to level out the ambiguous phase TEC results given in Equation (5).

$T E C_{\text {phase }}=\frac{f_{1}^{2} f_{2}^{2}\left(\emptyset_{2}-\emptyset_{1}-2 \pi\left(\lambda_{1} n_{1}-\lambda_{2} n_{2}\right)\right)}{40.3\left(f_{2}^{2}-f_{1}^{2}\right)}$

where, $2 \pi\left(\lambda_{1} n_{1}-\lambda_{2} n_{2}\right)$ is the bias due to ambiguity. The bias can be rewritten as a constant. Hence, final phase TEC is given as: 
$T E C_{\text {phase }}=\frac{f_{1}^{2} f_{2}^{2}\left(\emptyset_{2}-\emptyset_{1}\right)}{40.3\left(f_{2}^{2}-f_{1}^{2}\right)}+B$

where, $B$ is the unknown ambiguity. TEC equation is derived from the levelling of the ambiguous phase TEC with the pseudorange TEC, by subtracting the mean of the TEC phase, and adding the mean of the pseudorange TEC. TEC equation is represented in equation (7).

$T E C=T E C_{\text {phase }}-\overline{T E C_{\text {phase }}}+\overline{T E C_{\text {pseudorange }}}$

Practically, the pseudorange TEC measurement contains biases due to receiver noise. These biases can be calculated by using a differential code bias (DCB). This method of estimating TEC has been made possible due to the dispersive nature of the ionosphere. By measuring this delay using dual frequency GPS receivers, properties of the ionosphere can be inferred and these properties can be used to monitor space weather events such as GNSS, HF communications, Space Based Observation Radar and Situational Awareness Radar, etc. Therefore, GPS is a predominant technique of TEC measurement. Detailed explanation can be found in [8] and [7].

The availability of TEC from the Nigerian ionosphere has been made possible through Nigerian GNSS Reference NETwork (NIGNET) which was set up by the Office of the Surveyor General of the Federation (OSGoF). However, in the Nigerian equatorial sector, several station specific TEC measurements have been made from the past 6 years till present using data from a number of GNSS orbiting the space. This has led to studies and intensifying effort to understand the Nigerian equatorial ionosphere by scientist in the region. Hence, the aim of this study is to analyse and compare the behaviour of TEC in Northern (Zaria) and southern Nigeria (Enugu) both of which are located at the magnetic equator.

\section{MATERIAL AND METHODS}

In the Nigerian sector, which encompasses the equatorial latitude, the office of the surveyor general of the federation (OSGoF) has launched a project NIgerian GNSS reference NETwork (NIGNET, www.nignet.net). This is similar to the GPS Aided Geo Augmented Navigation (GAGAN) in operation in the Indian sector. Presently, NIGNET comprises of 15 dual frequency GPS receivers out of which 2 have been selected for this work. Figure 2 shows the location of both stations on the map of Nigeria: ABUZ (Zaria) located in the North and UNEC (Enugu) located in the South.

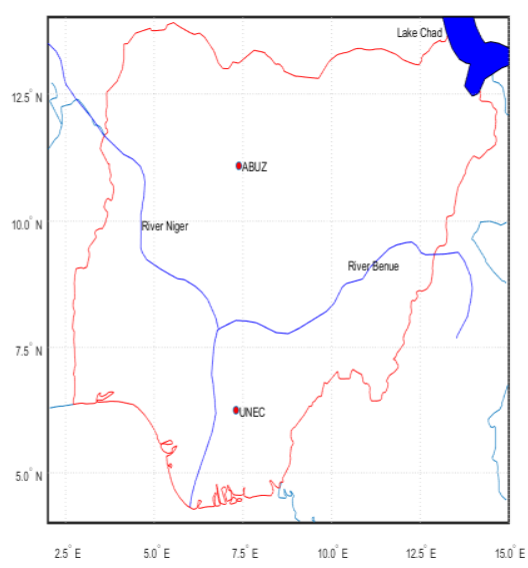

Figure 2: Location of stations used in the study.

Both stations were carefully selected because data availability during the period of study is high as shown in Figures 3. An ascending phase of solar cycle 24 corresponding to a moderate solar activity (MSA) year (2011) with sunspot number, $R z=55.7$ was used in this study. No major storm occurred in the year 2011, hence, it is considered a solar quiet year. This is with the view to study the temporal and spatial variation of TEC in the Nigerian equatorial ionosphere, where the longitudinal coverage of both stations varies from $7.30^{\circ} \mathrm{E}$ to $7.39^{\circ} \mathrm{E}$ and the latitudinal coverage varies between $6.25^{\circ} \mathrm{N}$ and $11.09^{\circ} \mathrm{N}$.

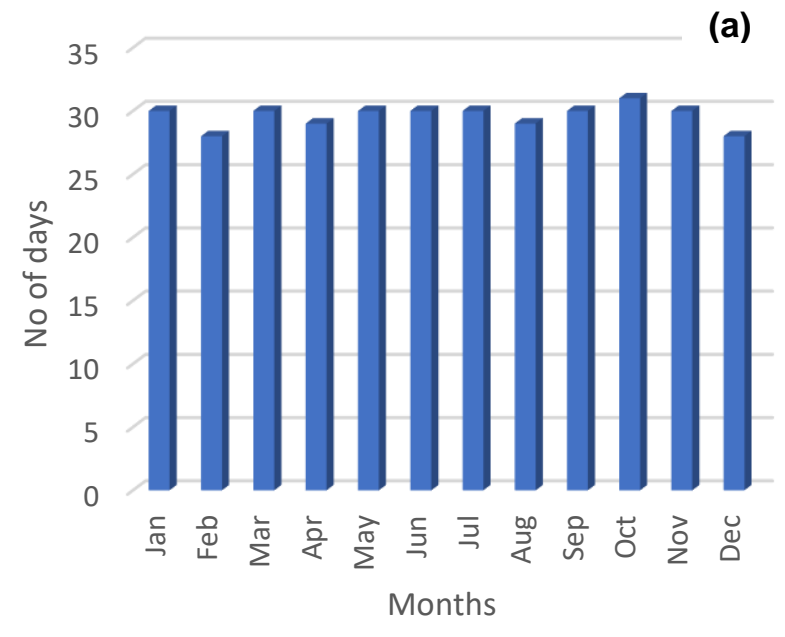


(b)

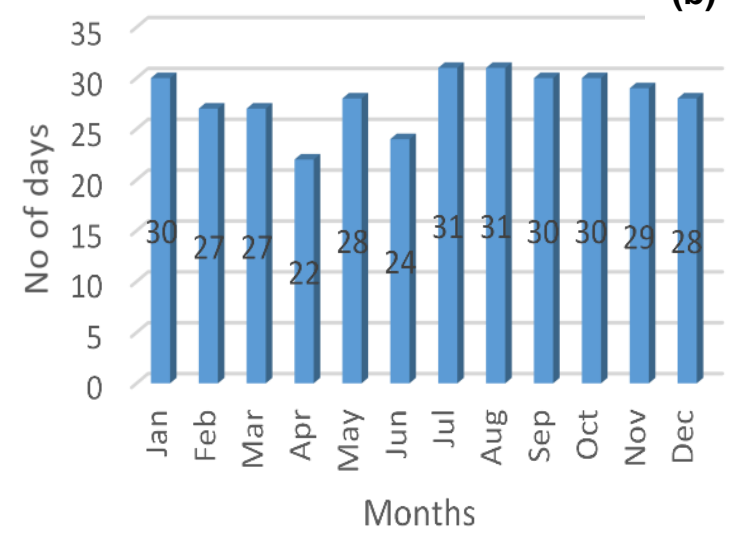

Figures 3: Number of days of data availability at

(a) ABUZ station and (b) UNEC station.

Receiver Independent Exchange (RINEX) files in compressed format were downloaded from NIGNET server. The files were unzipped and further processed using the CRX2RNX Hatanaka and Gopi or GPS_TEC developed by $\mathrm{Dr}$ Gopi Seemala of Boston College in Texas [19] to obtain the required TEC values. Values of vertical TEC at 1 minute time resolution using dual frequency $(1575.42,1227.6 \mathrm{MHz})$ GPS receivers were obtained and were converted into hourly TEC values used in this analysis. Figures 4 shows the flow chart of the method process used in the study.

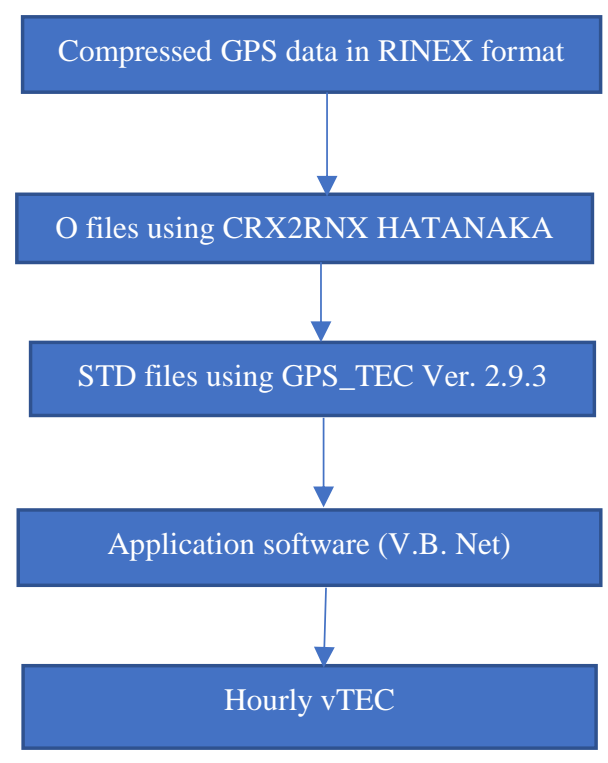

Figure 4: Flow chart for TEC calculation.
Mean vTEC (in TEC units of $10^{16} \mathrm{el} / \mathrm{m}^{2}$ ) during the four seasons at both stations for all hours of the day were plotted against each hour of the day. Also, variability of VTEC is evaluated from the hourly mean $(\mu)$ of vTEC and its corresponding standard deviation $(\sigma)$ by using the approach of [15], [18], [6], [22], [23], [24].

$\operatorname{VR}(\%)=\frac{\sigma}{\mu} \times 100$

This method of determining variability shows that the deviation of all daily values from the monthly mean (or median) is considered. This indicates that the whole data is used [22], [23]. Analyses of vTEC variability will also be considered on diurnal and seasonal scales.

\section{RESULTS AND DISCUSSION}

The diurnal variations of mean VTEC in the Nigerian ionosphere shows unique features as those of a typical equatorial ionization anomaly (EIA) station as illustrated in Figures 5. This figure shows a clear distinction between daytime and nighttime values with a steep increase starting from sunrise and reaches its daytime peaks between $13-15 \mathrm{LT}$ at UNEC. At ABUZ, TEC reached its daytime peak between 14 - 16 LT [17], [4], [14], [13], and falls to a minimum at sunset. This is similar to results obtained during low solar activity in the EIA region, which have been attributed to the increase in strength of the Equatorial Electrojet (EEJ), EUV flux, geomagnetic activity [11], [4] and thermospheric effects which is a major contributor to the daily variations in TEC [17], [3]. Dawn depression is well defined at both stations. Dawn depression is in the range of $3-7$ TECU at UNEC and 5- 7 TECU at ABUZ station. The dawn depression occurred at the same local time of $04 \mathrm{LT}$. Pre-midnight values $(7-26$ TECU) were slightly higher than post-midnight values $(3-13$ TECU) at ABUZ, but at UNEC, there is a significant difference in pre-midnight values (11 - 29 TECU) and post-midnight values (3 13 TECU). Furthermore, the diurnal variation in TEC shows a minimum to maximum variations of approximately 3 to 49 TECU which corresponds to 1 to $\sim 8 \mathrm{~m}$ of range delay, and 3 to 55 TECU also corresponding to about 1 to $\sim 9 \mathrm{~m}$ range delay at the GPS L1 $(1.575 \mathrm{GHz})$ frequencies in Northern Nigeria (ABUZ station) and south (UNEC station) respectively. This is similar to results obtained by [1] during low solar activity.

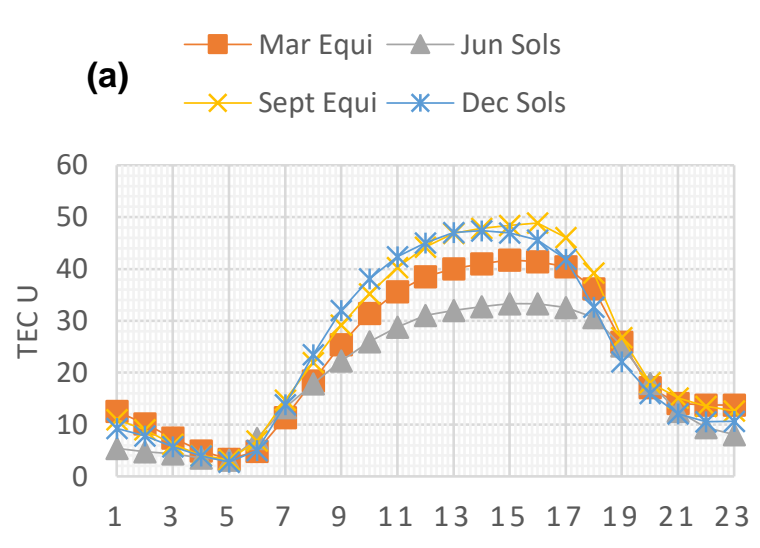




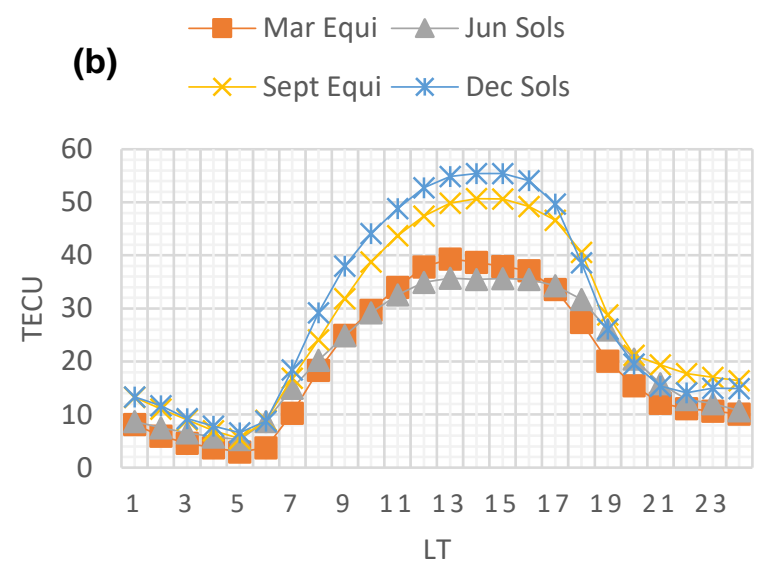

Figure 5: Diurnal variation of TEC for different seasons at (a) ABUZ station and (b) UNEC station.

Dome shaped daytime profiles are observed at both stations, this might be different from the daytime shape of TEC at stations located on the crest and trough of the EIA. On a seasonal scale, September Equinox and December Solstice values which are about same range, were higher followed by March Equinox while least values were recorded during the June Solstice season at ABUZ station, while at UNEC, September Equinox and December solstice values were higher than those of March Equinox and June Solstice. Pre- and postmidnight values were highest during the Equinoxes, followed by December solstice and least in June Solstice season at ABUZ. Pre- and post-midnight values were also higher during the Equinoxes than the Solstice season at UNEC, although they are about the same range. This could be as a result of the $E \times B$ drift velocities which are reported to be larger in the equinoctial months than the solstice months, hence, resulting in the semiannual variation of TEC [5]. They further suggested that the intensity of the electrojet strength obtained from the Horizontal component maybe responsible for the semiannual day-to-day variation of TEC. [17] reported that there is a correlation between the semiannual variation and the solar zenith angle and magnetic field geometry.

Figure 6 shows the percentage deviation from the monthly mean of TEC for ABUZ and UNEC respectively, using equation 3 . It is observed that nighttime variability is higher than daytime variability with not well defined pre-midnight and post-midnight peaks for the four seasons at both stations. March Equinox post-midnight peak of $69 \%$ and June Solstice pre-midnight peak of $47 \%$ were observed at ABUZ station while at UNEC, December Solstice postmidnight peak of $91 \%$ and March Equinox pre-midnight peak of $47 \%$ were observed. During the day, March Equinox, June Solstice and September Equinox variability values were about the same which were higher than those of December Solstice at ABUZ station. At UNEC station, March Equinox recorded highest variability, followed by December Solstice and the least variability is observed during the June Solstice and September Equinox seasons.
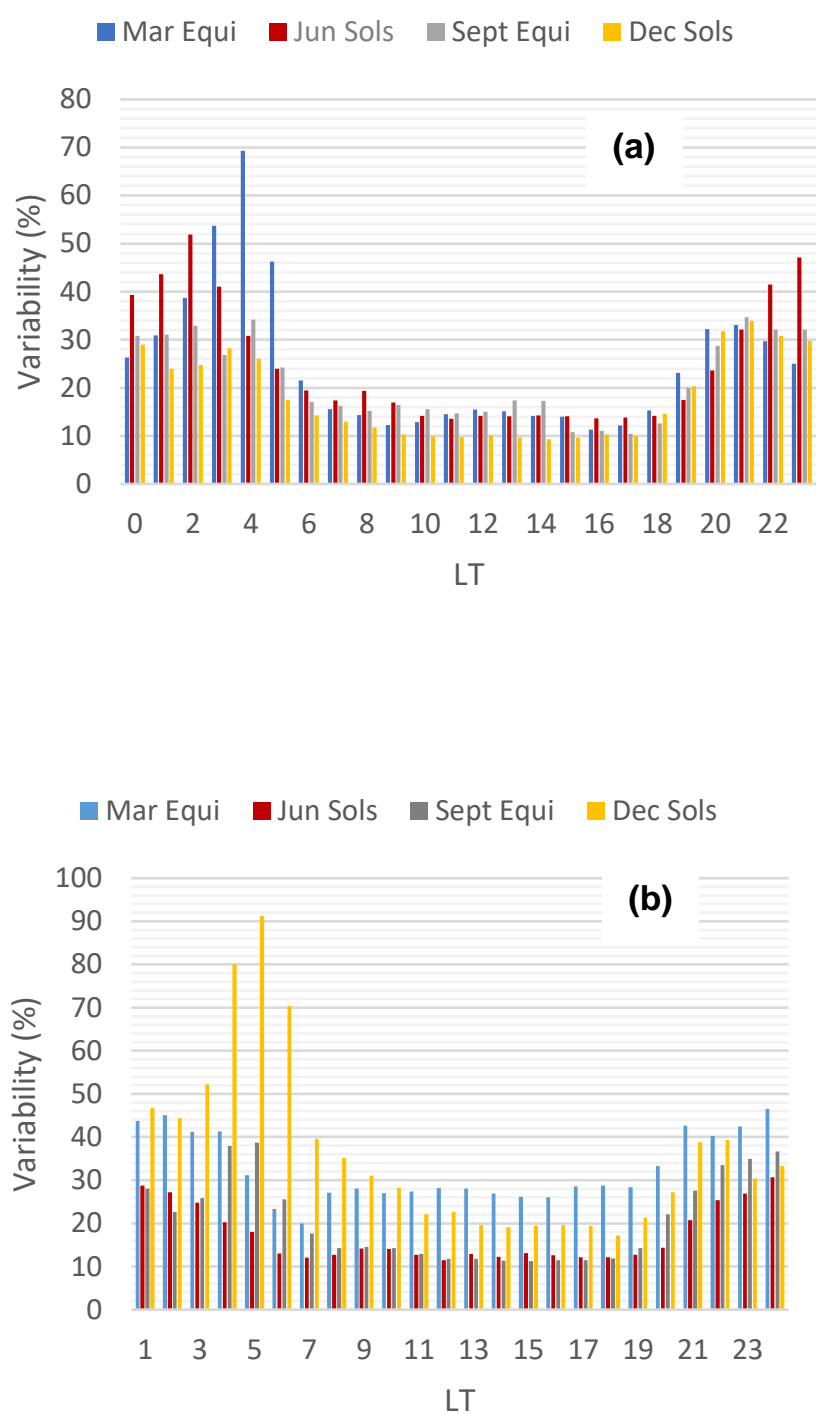

Figure 6: Percentage deviation from monthly mean of TEC for different seasons at (a) ABUZ station and (b) UNEC station.

Night-time variability could be as a result of thermospheric neutral wind, temperature gradient, Rayleigh-Taylor plasma instability [18], [10], [3] while variability of TEC during the day is reported to be influenced by the electric field strength which gives rise to the $E \times B$ uplift of ionization leading to EIA [20] and Meridional winds [25]. They also reported that electric field perturbations and thermospheric winds producing fluctuations in the ionospheric $E$ and $F$ regions are the main causes of day - to - day variations in ionospheric parameter.

Finally, TEC values are observed to be slightly higher for all hours and seasons at Enugu in the south than Zaria in the north except during March equinox at Zaria where TEC values were higher during the daytime. This could be as a result of their location with respect to the 
magnetic equator which implies that there could be little variations in TEC even within the same latitudinal zone.

\section{CONCLUSION}

We present results of diurnal and seasonal variation of mean TEC and its variability over Northern Nigeria (Zaria) and Southern Nigeria (Enugu). The results show a unique behaviour of mean TEC at both locations. There is a steep increase starting from sunrise and reaches its peak in the afternoon and falls to a minimum at sunset during the ascending phase of solar cycle 24 corresponding to a moderate solar activity year (2011) with $R z=55.7$. The diurnal variation of TEC shows a minimum to maximum variations of approximately 3 to 49 TECU which corresponds to 1 to $\sim 8 \mathrm{~m}$ of range delay, and 3 to 55 TECU also corresponding to about 1 to $\sim 9 \mathrm{~m}$ range delay at $\mathrm{ABUZ}$ station and UNEC station in the Nigerian equatorial ionosphere (NEI) respectively. The study reveals semiannual day-to-day variation of TEC resulting from the solar zenith angle and the magnetic field geometry. On the seasonal behaviour, mean TEC of December Solstice and September Equinox were higher than those of March Equinox and June Solstice at both stations. Pre- and post-midnight values were highest during the Equinoxes, followed by December solstice and least in June Solstice season. Furthermore, the percentage deviation from the monthly mean of TEC reveals two characteristic peaks which are not well defined for the four seasons at both stations i.e. the pre-midnight and post-midnight. It is observed that nighttime variability is higher than daytime variability.

\section{ACKNOWLEDGEMENTS}

We thank the Office of the Surveyor General of the Federation (OSGoF) for setting up the Nigerian GNSS Reference Network (NIGNET) which provides TEC data for scientific research. We also thank Gopi Krishna of Boston College, USA and Dr Wusu of Lagos State University, Nigeria for providing software used for TEC processing and analysis.

\section{COMPETING INTERESTS}

Authors have declared that no competing interests exist.

\section{AUTHORS' CONTRIBUTIONS}

Author A designed the study, obtained and analysed data, wrote the protocol, and wrote the first draft of the manuscript. All other authors managed the literature searches, read and approved the final manuscript.

\section{REFERENCES}

[1] Abba I, Abidin WAWZ, Masri T, Ping $\mathrm{KH}$, Muhammad MS, Pai BV. Ionospheric effects on GPS signals in low-latitude region: $A$ case study review of
South East Asia and Africa. Nigerian J. of Technology. 2015: 34: 523 - 529.

[2] Akala AO, Somoye EO, Adeloye AB, Rabiu AB. lonospheric $f_{0} F_{2}$ variability at equatorial and low latitudes during high, moderate and low solar activity. Indian Journal of Radio and Space Physics. 2011: 40: $124-129$

[3] Ayorinde TT, Rabiu AB, Amory-Mazaudier C. Interhourly variability of total electron content during quiet condition over Nigeria, within the equatorial ionization anomaly region. J. Atmospheric and Solar-Terrestrial Physics. 2016: 145: $21-33$.

[4] Bagiya MS, Joshi HP, lyer KN, Aggarwal M, Ravindran S, Pathan BM. (2009). TEC variations during low solar activity period (2005-2007) near the Equatorial Ionospheric Anomaly Crest region in India. Ann. Geophys. 2009: 27: 1047-1057.

[5] Bolaji OS, Adeniyi OJ, Radicella SM, Doherty PM. Variability of total electron content over an equatorial West African station during low solar activity. Radio Science. 2012:47: RS1001.

[6] Bilitza D, Obrou OK, Adeniyi JO, Oladipo O. Variability of foF2 in the equatorial ionosphere. Adv. Space Res. 2004: 34: $1901-1906$.

[7] Carrano CS. GPS-SCINDA: A real-time GPS data acquisition and ionospheric analysis system for SCINDA. Atmosph. And Environ. Res., Inc., GPSSCINDA. 2007.

[8] Carrano CS, Groves K. The GPS segment of the AFRL-SCINDA global network and the challenges of real-time TEC in the equatorial ionosphere, ION NTM, Monterey, California 2006: 1036 - 1047.

[9] Ciraolo L, Azpilicueta F, Brunini C, Meza A, Radicella $S$ M. Calibration errors on experimental slant total electron content (TEC) determined with GPS. SpringerVerlag. 2006.

[10] Chandra H, Sharma S, Soe WA. Day-to-day variability in the critical frequency of F2 layer over the anomaly crest region, Ahmedabad. Journal Indian Geophysical Union. 2009: 13: 217 - 226.

[11] Dabas RS, Bhuyan PK, Tyagi TR, Bhardwaj RK, Lal J B. Day-to-day changes in ionospheric electron content at lowlatitudes, Radio Sci. 1984: 19: 749-756.

[12] Davis K. lonospheric Radio Propagation. National Bureau of Standards Monograph. 2965: 80.

[13] D'ujanga FM, Opio P, Twinomugisha F. Variation of total electron content with solar activity during the ascending phase of solar cycle 24 observed at Makerere University, Kampala. Space Weather: Longitude and Hemispheric Dependences and Lower Atmosphere Forcing, Geophysical Monograph 220, First Edition. Edited by Timothy Fuller-Rowell, Endawoke Yizengaw, Patricia H. Doherty, and Sunanda 
Basu. (C) 2017 American Geophysical Union. Published 2017 by John Wiley \& Sons, Inc. 2017.

[14] Fayose RS, Rabiu B, Oladosu O, Groves K. Variation of total electron content (TEC) and their effect on GNSS over Akure, Nigeria, Applied Physics Research. 2012: 4: 2.

[15] Forbes JM, Palo SE, Zhang S. Variability in the ionosphere, J. Atmos. And Solar Terr. Phys.2000: 62: $685-693$.

[16] Klobuchar JA. Ionospheric effects on Global Positioning System: theory and applications, I, ed. Parkinson BW, Spilker JJ. American Institute of Aeronautics and Astronautics, Washington, D.C., USA. 1996.

[17] Rama Rao PSV, Gopi Krishna S, Niranjan K, Prasad DSVVD. Temporal and spatial variations in TEC using simultaneous measurements from the Indian GPS network of receivers during low solar activity period of $2004-2005$, Ann. Geophys. 2006: 24: 3279 $-3292$.

[18] Rishbeth $H$, Mendillo $M$. Patterns of $F_{2}$-layer variability Journal of Atmospheric and Solar-Terrestrial Physics Volume. 2001: 63: (15): 1661-1680

[19] Seemala G. Rinex GPS-TEC program, version 2.2, Boston College. Retrieved on June 15, 2017. Available: https://seemala.blogspot.com/

[20] Somoye EO. Appropriate film speed for ionospheric fading records from winds equipment. Asian J. of Scientific Research. 2010: 3: (1): 31 - 38.

[21] Somoye EO, Akala AO, Ogwala A. Day-to-day variability of h'F and foF2 during some solar cycle epochs. Journal of Atmospheric and solar Terrestrial Physics. 2011: 73: 1915 - 1922.

[22] Somoye EO, Akala AO, Adeniji-Adele RA, Iheonu EE, Onori EO, Ogwala A. Equatorial F2 characteristic variability: A review of recent observations. Advances in Space Research 2013a: 52: 1261-1266.

[23] Somoye EO, Akala AO, Onori EO. Comparison of foE and M(3000)F2 variability at Ibadan, Singapore and Slough. Journal of Atmospheric and solar Terrestrial Physics 2013b: 92: 18 - 22 .

[24] Somoye EO, Akala AO, Ogwala A, Onori EO, Adeniji-Adele RA, Iheonu EE. Longitudinal dependence of day-to-day variability of critical frequency of equatorial type sporadic $E\left(f_{o} E_{s q}\right)$. Space Weather: Longitude and Hemispheric Dependences and Lower Atmosphere Forcing, Geophysical Monograph 220, First Edition. Edited by Timothy Fuller-Rowell, Endawoke Yizengaw, Patricia H. Doherty, and Sunanda Basu. (C) 2017 American Geophysical Union. Published 2017 by John Wiley \& Sons. Inc. 2017.

[25] Suranya PL, Prasad DSVVD, Niranjan K, Rama Rao PVS. Short term variability in foF2 and TEC over low latitude stations in the Indian sector, Indian Radio Journal and Space Physics. 2015: 44: 14 - 27. 